\title{
Perceived Adherence to Professional Ethics and Associated Factors Among Health Professionals in Bale Zone Public Hospitals, Oromia Regional State, South-East Ethiopia
}

\author{
Abiru Neme Neme ( $\nabla$ abiruneme@gmail.com ) \\ Jimma University College of Public Health and Medical Sciences \\ Desta Workineh Workineh \\ Jimma University College of Public Health and Medical Sciences \\ Bethlehem Getachew Getachew \\ Medawalabu University
}

Research article

Keywords: adherence, professional, Bale Zone

Posted Date: August 9th, 2019

DOI: https://doi.org/10.21203/rs.2.12522/v1

License: (c) (1) This work is licensed under a Creative Commons Attribution 4.0 International License.

Read Full License 


\section{Abstract}

Introduction: Currently, hospitals not only have to contend with the dynamics of regulation but most importantly they have to deal with the issue of professional ethics. Objective: The objective of this study is to assess perceived adherence the professional ethics and associated factors among health care professionals in hospitals found in Bale Zone, Oromia region, South East - Ethiopia. Methods: A hospital based cross-sectional study was employed from April to May 2019in hospitals found in Bale Zone. All medical doctors, nurses and midwives who involved in patient treatment and care in the different units of the hospitals during data collection. The edited and cleaned data entered into a computer using SPSS version 20.0 software and a summary descriptive statistics and binary logistic regression was performed. Those variables which had significant association in bivariate logistic regression analyses were taken to multiple logistic regression models to identify variables which has independent association with the dependent variable (perceived adherence to professional ethics). All statistical tests were declared at pvalue less than 0.05 . Results: From the total of 417 questionnaires distributed to different health care units in the hospitals, the analysis was done for 408 responses which give a response rate of $97.8 \%$. Overall, 186(45.6\%) respondents had good perceived adherence of ethical practice. Nurse profession $(A O R)=3 ; 95 \% \mathrm{Cl}=1.17-7.76)$,Midwife profession $(A O R)=4 ; 95 \% \mathrm{Cl}=1.19-11.40)$, negative attitude towards professional ethics (AOR $=2 ; 95 \% \mathrm{Cl}$ : 1.03, 2.52), insufficient information about professional ethics in the curriculum ( $A O R=2 ; 95 \% \mathrm{Cl}: 1.08,2.97)$ and those whose work experience less than three years $(\mathrm{AOR}=2.5 ; 95 \% \mathrm{Cl}: 1.32,4.75)$ were associated with poor adherence to professional ethical practice Conclusions: This study highlight the overall ethical practice among Bale zone health professionals is low. Profession, work experience, perceived inadequacy of professional ethics curriculum and attitude had statistically significant association. Need staff's attitude towards professional ethics, considering the intensity of $\mathrm{CRC}$ training for different professionals differently and revising the contents of professional ethics in the respective curriculums. Key words: adherence ,professional, Bale Zone,

\section{Background}

Ethics is defined as a set of moral principles which clarify what is morally right and what is morally wrong and also has been described as the science of morals and rules of conduct recognized in human life.(1)

Health professional ethics is concerned with moral principles, values and standards of conduct related to health care services(2). Adherence to professional ethics is the commitment of health professionals to treat their client without discrimination based on race, age, color, religion, ethnicity, national or social origin, sex, handicap and source of payment or other status(3). Other ethical concerns related to health care delivery in clinical setting are professional integrity, confidentiality, respect, compassionate, equality and equity $(2,4,5)$.

Researches revealed that factors like lack of proper information among patients on health service provision, weak supervision and poor complaint mechanism contributes for the health professions poor 
adherence to ethics in developing countries $(6,7)$.

Health care providers need an awareness of professional ethics more than ever before. Because adherence to professional ethics by health care workers is one of the most critical aspects of quality health service delivery as it involves the way service providers interact with service users $(4,5,8)$. Unethical behaviors among health professionals affects the accessibility of quality health services as it creates conflict in the relationship between health workers and health service users $(3,9)$.

In other words, non-adherence to professional ethics by health workers do not only affect the quality of services citizens receive but also erodes the reputation of health professionals and all other officials in the health system. Such a negative perception may further hinder the people's access to public health services $(3,10)$. Health care should be safe, effective, patient-centered, timely, efficient and equitable. These requisites of quality care are not only synergistic with ethics, but ethical concepts and reasoning are the foundation behind most current definitions of healthcare quality $(4,8)$. A patient centered approach to healthcare means providing a respectful patient's preferences and values through a shared decision make process. Such an approach is based on the ethical principles of autonomy and selfdetermination and is delineated in most healthcare organizations' ethical standards of practice, an informed consent policy $(3,11)$.

Encouraging health professionals to behave more empathically and less formally with their patients' needs identification of potential factors affecting their behavior in the health care setting. Therefore the primary objective of this study is to assess adherence of professional ethics among health professionals and identify factors associated with health professional ethics in hospitals found in Bale zone.

The patient has the right to self-determination, to make free decisions and the physician will inform the patient about the consequences of his/her decisions $(2,8,20)$. Despite this most health care providers don't provide informed consent for their patient. For instance one cross sectional study conducted among Iranian midwives shows that $87 \%$ of the pregnant mothers never received any information about the type of the childbirth, the advantages/disadvantages of different childbirth methods, their rights during pregnancy and childbirth after delivery.(25)

Providing the best possible care to the patients in the most ethical manner may find it difficult to balance the right to information with the need to avoid information overload(11). One challenge is how much information is adequate and how should complex medical information be communicated to patients who may be frightened or feeling ill, and may have trouble assessing risks, benefits and alternatives. Even, not all patients want a great deal of information. Some may prefer to trust their health provider to do what is best for them $(12,21)$. It is also common for health care professionals to clash with the family of the patients for whom they care over treatment decisions(22). 
Confidentiality is also both an ethical and a legal issue. Keeping information about a patient confidential is a way of showing respect for the person's autonomy. Because there is wide agreement that people have the right to control who has access to their information about them $(11,21,24)$. In another way, the ability to provide high quality medical care depends on patients feeling free to communicate fully and truthfully with their caregivers. Furthermore, individuals could face stigmatization and discrimination if certain medical information, such as about sexually transmitted diseases or mental illness, is not carefully protected $(12,14)$. Therefore, all identifiable information about a patient's health status, medical condition, diagnosis, prognosis and treatment and all other information of a personal kind, must be kept confidential, even after death $(11,26)$. A cross sectional study conducted among Nepalese nurses and a doctor shows that only $2.5 \%$ doctors and $11.6 \%$ nurses agreed that adhering to confidentiality of patients is important(27).

Therefore, medical ethics must be understood as an essential branch of general ethics, offers a valuable framework in which to define the norms for medical care(28). Thus, medical ethics is concerned with promoting health and medicine and clarifying norms for improving relationships between patients and health professionals $(2,12)$. Because, the statements of medical ethics require the health professional to do what is best for the patient and place the patient's interests before their interests. Above all, the purpose of medical ethics is to protect and defend human dignity and patients' rights $(13,14)$. Despite this a report in Tanzania health facilities shows that 1 of 4 people in need of health services in these areas are routinely asked to give bribes(5).

Just like other public servants in Ethiopia, health workers are also bound by the legal and and ethical requirements. Basically, the act and codes of Ethics urge all health workers to avoid unethical practices in their working environment (29).Despite the presence of the act and codes of Ethics, incidents of failure to observe professional ethics continue and are particularly pronounced in Ethiopia calling for an end to these malpractices. The government, on its part, has been vainly promising to address the problem through imposition of tough measures against anyone found misbehaving $(3,29)$.

A Score Card Report on 45 Health Facilities in Tanzania reveals factors like unavailable or non-functional hospital ethics committee, weak supervision and poor management exacerbates poor adherence to professional ethics(5).

The problem of substance use has been common among health professionals due to their proximity to those drugs. It highly affects the medical practice and patient's safety. A study conducted in Jimma University among medical interns shows that $48.4 \%$ of them used substance in their life time $(32,33)$. Another study in western Amhara region shows that Professionals who drank alcohol were more likely to be dissatisfied by their job(34).

Health professionals that are more knowledgeable and have favorable attitude tend to have good ethical practice. A study conducted among doctors in Addis Ababa showed that knowledgeable medical doctors were more likely to have good practice of code of ethics and having good practice of code of ethics 
among medical doctors with favorable attitude were 7.404 times the odds of those with unfavorable attitude towards code of ethics(18).

For years, unethical behavior among health workers in Ethiopia has been reported and discussed by various stakeholders including the media, members of parliament, community leaders as well as institutions.

Generally Non-adherence to professional ethics among health workers, not only affect the whole process of accessibility and provision of quality health services to citizens, but also tarnishes the reputation of health professionals and all other officials in the health system. This situation must not be tolerated any further and must be eliminated at all costs.

\section{Methods}

Study Area and Period

A hospital based cross sectional study was conducted in Bale zone from March $1^{\text {st }}$ to April 30th, 2019. Bale zone is the second largest zone in Oromia regional state located in the South-eastern part of Ethiopia. The zone administratively divided in to 17 districts and 6 town administration. Based on bale zone health office report, there are four government hospitals (Goba, Robe, Ginnir and Delomena hospitals) and 76 functional health centers, 351 functional health post, 179 private clinic, 1 NGO clinic, 95 pharmacy/ drug shop, $1 \mathrm{NGO}$ drug shop and 4 medical drug store in Bale zone.Goba hospital is a referral teaching hospital while the remaining three are district hospitals. The total number of medical Doctors, Nurses and Midwives in Goba referral hospital, Delomena district hospital, Giinir district hospital and Robe district hospital are 219,100, 67 and 73respectively.

Study Design

A hospital based cross-sectional study was implemented in order to assess the perceived adherence to professional ethics among health care providersin four public hospitals found in Bale zone.

Population

\section{Source Population}

All medical doctors, nurses and midwives who were on duty in patient treatment and care in the different units of the respective hospitals.

\section{Study Population}

All medical doctors, nurses and midwives who fulfil the inclusion criteria in four public hospitals were employed in the study. 
Those medical doctors, nurses and midwives who had more than 6 months work experience were be included in the study.

\section{Exclusion criteria}

Medical doctors, nurses and midwives who were on annual leave during data collection time

Sample Size Determination

Since the number of health professional found in Bale zone public hospitals were manageable, all medical doctors, nurses and midwives that fulfilled the inclusion criteria were employed in the study which is 417 in number.

Data collection tools and techniques

Survey instruments were adapted from Patient Safety Indicators (PSIs) survey tools for provider and arealevel indicators, and patient safety culture survey instrument of Agency of Healthcare Research and Quality (AHRQ) [11] .Some of the questions are adapted from Center for Ethics in Health Care (NCEHC) integrated ethics staff survey and also using different literatures $(7,9,18,27,35)$

Data was collected using self-administered questionnaire. Well-structured and pretested questionnaire was given for health professionals as self-administered questionnaire. Respondents who give their written informed consent were given the questionnaire and were asked to complete and return it. The first part of the questionnaire focuses on the respondents' socio-economic status. The second part of the questionnaire was assessing the knowledge of healthcare ethics and their perception toward it. In the third part, their experiences on health care ethics was assessed.

Variables

\section{Dependent Variables}

Perceived adherence to professional ethics

\section{Independent}

Educational status, attitude, knowledge on professional ethics, monthly income, service year, types of profession, type of college/university, marital status, preference during department selection, substance use, satisfaction, type of hospital, violence

Data Quality Control

To assure the quality of the data the following activities were done. Four BSc nurses were recruited and trained for one day for facilitation and two BSc health officers were assigned as supervisor. Before the actual data collection, the structured questionnaire was pre-tested at Dodola hospital. The pre-test was 
done on 20 health professionals, and at the end of every data collection day each questionnaire was examined and pertinent feedback was given to the data collectors and supervisor.

Data entry and analysis

Data entry was carried out by an experienced data entry clerk with close supervision by the principal investigator. Data cleaning and screening was conducted exclusively by the principal investigator. Before starting the analysis, the data needs to be prepared and cleaned. The edited and cleaned data was entered into a computer using SPSS version 20.0 software and a summary descriptive statistics and binary logistic regression and multivariate logistic regression were done.

Bivariate and multiple logistic regression analyses were done to identify the relationship between the dependent variables (adherence to professional ethics) and independent variables. Those variables which had significant association in bivariate logistic regression analyses was taken to multiple logistic regression models to identify variables which has independent association with the dependent variable. All statistical tests will be declared at p-value less than 0.05 .

\section{Ethical Clearance}

Ethical clearance was obtained from Jimma University. Permission letter was obtained from Bale zone health department. Participation in the study was on voluntary bases and oral consent was obtained from study participants to confirm their willingness. All the information provided by the study participants were kept confidential. Data were collected in a way that makes it impossible or at least very hard to identify the respondent and question that contain information that could be used to identify the surveyed persons was removed.

Dissemination

This will be disseminated to Bale Zone health department, Jimma university and other profit or non-profit organizations/ parties in devising effective policies aimed at decreasing non-ethical practice in public hospitals. Attempts will be made to publish the article in peer reviewed journal and to make presentations in scientific conferences.

\section{Results}

Socio Demographic Characteristics

Total of 417 survey questionnaires distributed to different units in the hospitals from which nine incomplete questionnaires were excluded. Finally, 408 (262 male and 146 female) participants completed survey questioners and considered for the analysis which gives a response rate of $97.8 \%$. The mean age of the participants was 30.5 ( \pm 5.7 years). The majority health professionals $258(63.2 \%$ ) were in the 25.34 years age group and most of respondents 295(72.3\%) of the participants were Oromos, whereas 211(51.7) were Orthodox Christians. 
Regarding respondent's salary, 196(48\%) of the participants' monthly salary was 3250-5414 birr per month. In addition, 1,916 and 11,722 Birr were the minimum and the maximum monthly salary of the respondents respectively, with the median monthly salary of 5006 Birr. Moreover, the minimum and maximum monthly allowances were 0 and 3500 Birr respectively.

The general characteristics of the study respondents are presented in (Table 1).

Professionalism and other factors

From the total respondents $94(23 \%)$ were not happy with their current profession and $120(29.4 \%)$ didn't choose their current profession when they joined the university. More than half of them $221(54.2 \%)$ were not ready to recommend others to pursue their current profession.

Ethics committees are institutional structures that provide a deliberative forum in which ethical issues can be analyzed and addressed. Majority of participants $237(58 \% \%)$ did not know about the existence of the ethics committee in their hospitals. Among those who knew the existence of ethics committee in the hospital, more than half, 92 (53.8\%) of them didn't know the function of the committee while around $31(18.14 \%)$ replied correction measure as the main task of the committee. Regarding training opportunity, only $131(32.1 \%)$ of the respondents were taken professional ethics training.

Most of the respondents 341 (83.6\%) mentioned college/university as the main source of information for professional ethics. Regarding the professional ethics course in previous educational curriculum $284(69.6 \%)$ of the respondents replied that it was not adequate.

Majority of the respondents replied that they encounter ethical problems in their institutions from time to time $238(58.3 \%)$. About $143(35 \%)$ of them have been accused regarding issues related with professional ethics. Religious related issued mentioned as the most common ethical dilemma faced by health care providers $149(36.5 \%)$ followed by discharge against medical advice $137(33.6 \%)$. Workload was stated as the main reason for unethical behavior of care providers $298(73 \%)$.

More than half of hospital administrators don't communicate professional ethics as a priority issue $206(50.5 \%)$ and $222(54.4 \%)$ of the respondents said the promotion decision doesn't consider ethical practice. $92(47.1 \%)$ of participants stated that their relationship with managers unfairly influence their ethical practice. More than quarter of the professionals $152(37.3 \%)$ reported that there is frequent conflict among colleagues.

From the total respondents $75(18.4 \%)$ of them reported that were harassed by their clients while $56(13.7 \%)$ of them stated that they received gifts from their patients. About $88(21.6 \%)$ of study participants used substances in their life and more than half of them used alcohol 54(61.4\%). (Table 2)

Knowledge towards professional ethics 
Majority of the respondents $314(77 \%)$ said that they can't define professional ethics but most of them agreed 370(90.7) that professional ethics is an important subject. Significant number of participants $305(74.8 \%)$ stated that the right of patient should always be recognized but $180(44.1 \%)$ of them replied that disclosure of medical report is important. About 354(86.8\%) of professionals reported that the patient has the right to know about his/her problem in person. From the total respondents $177(43.4 \%)$ of them mentioned that they disclose medical error only if it caused a major harm. More than half of the respondents $217(53.1 \%)$ reported that being unethical to patient leads to legal action. The mean score knowledge about professional ethics was $5.65(S D=1.7)$. Overall, more than half of the respondents 229(56.1) were knowledgeable (Table 3).

Attitude Towards Professional Ethics

From the total respondents, $149(36.5)$ agreed to the view that 'ethical conduct is important only to avoid legal action' and $215(52.7 \%)$ of the respondents agreed that the patients' wishes should be adhered. About $195(47.8 \%)$ of the respondent agreed that 'patient should always be told if something is wrong' while $119(29.2 \%)$ of them disagreed that close relatives must always be told about a patient's condition. Also $152(37.3 \%)$ of the respondents agreed to the view that health professionals should do what is best irrespective of patient's opinion and $161(39.5 \%)$ of the respondents disagreed to the view that patient's only need to consent for operations but not for tests or medications while 127(31.1) of the respondents disagreed that children should never be treated without the consent of their parents or guardians. Regarding non-compliant and violent patients, 115(28.2\%) disagreed that health professionals should refuse to treat patients who behave violently' and 154(37.7\%) disagreed that 'if patients refuse to undergo treatment due to their beliefs, they should be instructed to find another health profession'.

Regarding social clients, $138(33.8 \%)$ of the respondents disagreed treat social that treating social client first is correct and $173(42.4 \%)$ of them agreed that health professionals should resolve conflict with other health care providers (Table 3 )

The mean score of attitude towards professional ethics was $46.03(\mathrm{SD}=5.8)$. Overall about $184(45.1 \%)$ had a positive attitude towards professional ethics.

Ethical Practice of health professionals towards professional ethics

The degree to which health professions demonstrate behavior consistent with ethical practices in health care was measured using 15 questions. Those whose choice is 'always' earned score of 2 , sometimes earned 1 and never earned 0 with a total of 30 marks. Participants who score equal or above the mean are considered had good practice and below the mean had poor practice.

The mean score of ethical practice was $17.18(S D=3.24)$. The range of respondents' practice scores was 9- 27. Accordingly, in this study, 258(63.2\%) of health workers were taking informed consent before any treatment. However, only $148(46.3 \%)$ of the respondents always used private rooms for patient examination. Majority, $267(65.4 \%)$ of the participants always Showed respect, dignity and attention to 
patient's health need but only $115(28.2 \%)$ Of them always introduce their name, professional title and their role before providing service. Over all 186(45.6\%) respondents had good ethical practice (Table5)

Job satisfaction

From the total respondents $137(33.6 \%)$ were satisfied with the availability of equipment needed for work in their department while 146(35.8\%) of them stated that they were satisfied by the time given for the accomplishment of their task. Half 204(50\%) of the respondents reported that they were satisfied with their interpersonal relationship with their colleagues. About 175(42.9\%) of them were very dissatisfied by their salary. Regarding the issue for continuous professional education 124(30.4\%) of them were satisfied (Table 5). The mean score of satisfaction towards one's job was 20.32(SD=4.81). Overall almost half of the respondents 201(49.3\%) were satisfied by their job.

Factors associated with ethical practice

To identify factors associated with good ethical practice a multivariate logistic regression model was fitted with the variables having a p-value $<0.05$ in the bivariate logistic regression analysis. Accordingly, some variables were remained independently associated with good ethical practice after controlling other factors. From these factors, Nurses were three times more likely to have poor ethical practice (AOR $=3.01$; $95 \% \mathrm{Cl}: 1.17,7.76)$ and Midwives were 4 times more likely to have unethical practice $(\mathrm{AOR}=4.11 ; 95 \% \mathrm{Cl}$ : $1.19,11.4)$ than Physicians. Negative attitude towards professional ethics had statistical significant association with ethical practice $(\mathrm{AOR}=1.61 ; 95 \% \mathrm{Cl}: 1.03,2.52)$.In addition, those respondents who responded as the ethical information from the curriculum is not adequate were more likely to be unethical $(A O R=1.79 ; 95 \% \mathrm{Cl}: 1.08,2.97)$ and those whose worked less than three years 2.5 times more likely to be unethical $(\mathrm{AOR}=2.5 ; 95 \% \mathrm{Cl}: 1.32,4.75)$

\section{Discussion}

Adherence to professional ethics by health care workers is the core aspects of quality health care delivery as it involves the way service providers interact with service users. But, only $45.6 \%$ of the professionals had good perceived practice towards professional ethics which is nearly similar with study conducted among Egyptian residents which is $48 \%(16)$ and greater than other similar studies conducted in Ambo town and Addis Ababa city which showed $24 \%$ and $30.4 \%$ adherence level to professional ethics respectively $(18,37)$.The discrepancy might be due to the small sample size and the implementation of CRC program by the federal ministry of health. Another nationwide study on respectful maternity care in public facilities reported $36 \%$ of the health professionals committed at least one form of mistreatment of women (38). For instance, though informed consent is a vital component of present-day health care ethics and a means of exercising patients right to self-determination, only $41.4 \%$ of professionals always obtain informed consent before rendering any service. This is nearly similar with study conducted in Addis Ababa which is $34 \%$ (18). Breaches of patient confidentiality or right to privacy and end-of-life decision-making are common ethical problems reported by other study (39). 
Though knowledge towards professional ethics is very important asset for ethical practice, overall only $56.1 \%$ had good knowledge towards professional ethics. The result is similar to the study in Mexico (40). Similar study in Ghana showed that $74 \%$ of the study participants had good knowledge towards health care ethics (41) which is relatively greater than this research result. The difference might be due to socio economic and cultural difference among health care professionals. But, the result from another study in ambo town revealed good knowledge level of $31 \%$ which is less than this research result (37). This difference might be the impact of CRC training provided all over the country regarding ethical practice and awareness for health professionals. Another study which is conducted in Addis Ababa among medical doctors showed that $75 \%$ of the study participants had good knowledge towards professional ethics (18) which is higher than this study. The difference might be because study was limited on doctors and conducted in capital city where information regarding professional ethics is easily accessible.

In relating to knowledge, in this study, about $77 \%$ of participants reported that they can't define professional ethics properly. In the contrary, about $86.7 \%$ Egyptian health professionals were able to define it which is very high (16). The discrepancy might be due to difference in study setting and study subjects. From the total respondents of this study, $61.5 \%$ of them were against the idea of physician assisted dying which is lower than study in Nepal which is $90 \%(27)$. Similar study in Ambo Town revealed that about $46 \%$ of the study participants were disagreed with assisting a patient who wants to die(37). Almost consistent result is reported from another study in Addis Ababa where 67.1\% participants disagreed that it is possible for nurses to help patients prepare for death using various psychological mechanisms(42).

The poor attitude towards professional ethics itself affects the ethical practice of health care professionals. Overall, only $45.1 \%$ of study participants had positive attitude towards professional ethics which is nearly similar with study in Ambo and Gondar towns which accounts $48 \%$ and $49.2 \%$ respectively $(37,43)$. The result is slightly lower than the study conducted in Egypt which is $60 \%(16)$. The inconsistency with study in Egypt might be due to difference in study setting and study subjects. For instance, in this study about $36.5 \%$ of participants agreed that ethics is only important to avoid legal action. Similar study conducted in sub-Saharan African countries revealed $41.7 \%$ which is nearly similar to this study agreed (13). In this regard, paternalistic attitude toward patient this study shows $47.8 \%$ of them disagreed for statement provider should do what is best for patient irrespective of patient opinion and about $52.7 \%$ disagreed to the view that patient wishes must always be adhered. The result is consistent with study conducted in India and sub-Saharan African countries $(13,44,45)$.

Confidentiality is both ethical and legal issue. It is crucial to maintain trust in client provider relationship. The maintenance and breach of confidentiality under certain specific circumstances is extensively discussed and stressed upon in medical code of ethics. However, this study revealed about $41.7 \%$ of respondents disagreed with the statement 'confidential information can only be disclosed if the patient gives explicit consent'. About $31.9 \%$ agreed that the patient information must be revealed for close a relative which is Similar with study in Ambo town(37). But different from Nepal that shows $77.1 \%$ which 
is higher (27), the difference might be due to the difference in sample size and sociocultural context in the study area.

In this study, the overall level of job satisfaction among health care professionals was $49.3 \%$. This finding is comparable with previous studies conducted in Ethiopia 54\% in Gondar (46) and 54.2\% in East Gojjam Zone (47). But, this result is lower than satisfaction rate reported in Nigeria and Nepal where the satisfaction level was $90.4 \%$ and $76 \%$ respectively (48), (49). The possible explanation for the above difference could be due to the difference in socio-economic status of the countries. Another nationwide qualitative study among healthcare workers in rural Ethiopia also concluded that healthcare workers experienced job dissatisfaction(50).

In this study, the socio-economic factors; respondents' educational status and work experience and other independent variables; attitude towards professional ethics, perceived adequacy of professional ethics in the curriculum, current profession, presence of ethics committee, receiving gifts from patients and love for the profession were showed significant association with professional ethics in the bivariate logistic regression analysis. From these independent variables, attitude toward professional ethics, current profession, perceived adequacy of ethics information from the curriculum and work experience were persistently associated with professional ethics in multiple logistic regressions analysis.

Similarly, unfavorable attitude is influencing the ethical practice in another study(18). But in contrast to this study, higher likelihood of performing high level ethical practice is found among midwives than other cadres (38). It is also reported that health professionals with fewer years of experience encountered ethical issues more frequently than others(39)

Another systematic review identified increased workload, lack of organizational support, training workshops, patient behavior, inappropriate role modelling as influencing factors for poor ethical practice (51).

\section{Conclusion And Recommendation}

Conclusion

The overall ethical practice of health care workers was low. Negative attitude toward professional ethics, perceived inadequacy of professional ethics curriculum, work experience and current profession have statistically significant association with ethical practice among health care workers in public hospitals of Bale Zone.

Recommendation

Depending on the result of this study the following recommendation were forwarded

- Government should give more emphasis and work on CRC training. 
- Hospitals should avail professional code of ethics documents to enhance knowledge of the employees, facilitate and give training educational opportunities and also, they should strengthen their Ethics committees.

- Universities should revise the content of professional ethics course in the curriculum.

- Finally, other researchers are recommended to conduct further investigation particularly the qualitative one to dig out more information regarding this issue.

\section{Strengths of this study}

- It is primary study

- Professional ethics is burning issue right now in all professions especially in health sector

- There was no similar study done in the study area

\section{Weakness of this study}

- Providers' practices were self-reported and their responses may have been tailored according to what they believed were appropriate.

- The attitude of health professionals towards health care ethics would be better investigated with qualitative study design.

\section{Declarations}

\section{Ethics approval and consent to participate}

The research proposal was approved by institutional review board of Jimma University, Jimma University Institute of Health. A permission letter was obtained from Bale zone health department.

\section{Consent to publish}

Not applicable

\section{Availability of data and materials}

All the data included in the manuscript has been included in the form of tables and figures. The deidentified raw data is not publicly available. But the de-identified raw data can be requested from the corresponding author after providing the necessary justification for request.

\section{Competing interest}

The authors declare no competing interest.

\section{Funding}


The study was funded by Jimma University Institute of Health $(\mathrm{JIH})$ throughout inception, data collection and analysis.

\section{Authors' contribution}

Abiru Neme, Bethlem Getachew and Desta Workneh contributed on data analysis, and checked the draft. Abiru Neme and Bethlem Getachew prepared manuscript. All authors read and approved the final paper.

\section{Acknowledgements}

We would like to thank the Bale zone health was conducted. Bale zone health for all the help and support given for us during the data collection period. We also thank Jimma university institute of health for permitting us to conduct this study.

\section{References}

1. Thomas A DG. Biomedical ethics. 4 ed1996.

2. Health Ethics: A critical dimension of WHO's work 2011 Contract No.: Ethics and Health Unit Newsletter.

3. Health sector transformation plan (HSTP) from 2015/16-2019/20. 2015.

4. Kiria I. HEALTH CARE WORKERS' ADHERENCE TO PROFESSIONAL ETHICS. 2012:1-32.

5. I K. Health care workers' adherence to professional

6. Charles O GN, Tom N, John W, Nelson S, and Damalie N. Nurses' knowledge in ethics and their perceptions regarding continuing ethics education: a cross-sectional survey among nurses at three referral hospitals in Uganda. BMC Research note2015:8:319.

7. Seetharaman Hariharan RJ, Errol Walrond and Harley Moseley. Knowledge, attitudes and practice of healthcare ethics and law among doctors and nurses in Barbados. BMC Medical Ethics 2006;7(7).

8. Hejaili HTaF. Professional Boundary Ethics Attitudes and Awareness Among Nurses and Physicians in a University Hospital in the Kingdom of Saudi Arabia. King Saud Bin Abdulaziz University for Health Sciences 2010.

9. S Hariharan RJ, J Gora. Knowledge, attitudes and practices of healthcare personnel towards CareEthics: A perspective from the Caribbean. The Internet Journal of Law, Healthcare and Ethics2006;5(1).

10. Gabel S. Ethics and Values in Clinical Practice. Mayo Clin Proc2011;86(5):421-4.

11. Global Network of WHO Collaborating Centres for Bioethics2015.

12. Booth W WP, Thompson. Legal and Ethical Issues in Medical Practice: Medical Assisting 3ed2009.

13. Kehinde F. Monsudi TOO, Abdulrasheed A. Nasir, Abdulkabir A. Ayanniyi. Medical ethics in subSahara Africa: closing the gaps. African Health Sciences 2015;15(2). 
14. Liang S JH, Weimin Y, Huafang L, Yifeng S, and Yifeng X. Ethics, patient rights and staff attitudes in Shanghai's psychiatric hospitals. BMC Medical Ethics 2012;13(8).

15. Cléa Adas Saliba GARBIN AJIG, Nemre Adas SALIBA. ANALYSIS OF THE ETHICAL ASPECTS OF PROFESSIONAL CONFIDENTIALITY IN DENTAL PRACTICE. Journal of applied oral science2008;16(1):75-80.

16. M. Mohamed MAG, A.A. Kassem Knowledge, perceptions and practices towards medical ethics among physician residents of University of Alexandria hospitals, Egypt. EMHJ2012;18(9).

17. Waju Beyene1 CJ, Morankar Sudhakar2 ASSESSMENT OF QUALITY OF HEALTH CARE IN JIMMA ZONE, SOUTHWEST ETHIOPIA Ethiop J Health Sci 2011;21(special).

18. Mesafint $T^{\star}$ BA. Practice of code of ethics and associated factors among medical doctors in Addis Ababa, Ethiopia. PLOSONE2018;13(8).

19. Biruk Lambisso WAMISHO MA, Yeweynehareg Feleke, Abiy Hiruy, Yeneneh Getachew. REVIEW OF THE THREE YEAR PROCEEDINGS OF THE HEALTH PROFESSIONALS ETHICS FEDERAL COMMITTEE OF ETHIOPIA: ANALYSIS OF DECISIONS ON MALPRACTICE FILES. BMC Medical Ethics2015.

20. Richard E. Ashcroft AD, Heather Draper,John R. McMillan. PRINCIPLES OF HEALTH CARE ETHICS Second Edition. 2007.

21. Wakefield DJ. Guide to Informed Decision-making in Healthcare:Queensland Health

22. Jonathan B Sm, Jennifer B, Peter S. Top 10 health care ethics challenges facing the public: views of Toronto bioethicists. BMC Medical Ethics2005;6(5).

23. pat kurtz RLB. Health and Ethics. jones and bartlett publishers2011.

24. William A Nelson. Handbook for Rural Health Care Ethics:A Practical Guide for Professionals. 2009.

25. Leila N SFV, Tahmineh F, Naser B The related factors of compliance to professional codes of ethics from midwives' perspective working in healthcare centers of Tehran-Iran pan african medical journal2018;30(40).

26. Dya Eldin M. Elsayed REMA. Medical Ethics: What is it? Why is it important? sudanese journal of publc health 2009;4(2).

27. Samaj A KP, Arja R. , Tara B, Bipin A and Shiva R. Knowledge, attitude and practice of healthcare ethics among resident doctors and ward nurses from a resource poorsetting, Nepal. BMC Medical Ethics2016;17(68).

28. B Unnikrishnan TK, Nithin Kumar, Vaman Kulkarni, Prasanna Mithra, T Rekha, Ramesh Holla, BB Darshan and Avinash Kumar Perceptions and Practices of Nursing Professionals towards Healthcare Ethics: A Pilot Study from Coastal South India. . RJPBCS 2015;6(4):1497

29. A proclamation to provide for food, medicine and health care administration and control, (2010).

30. N HK, Gautam B,Sonia P,Swasti T. Knowledge, attitude \& practices regarding Ethics \& Law amongst medical and dental professionals in Rajasthan - A Questionnaire study Journal of Dental and Medical Sciences 2014;13(5):109. 
31. Ali D LMaNN. Factors affecting professional ethics in nursing practice in Iran: a qualitative study. BMC Medical Ethics2015;16(61).

32. Desta E SM, Workneh D, Gashaw BT The Prevalence of Substance Use and Associated Factors Among Medical Interns of Jimma University, South West Ethiopia Journal of Substance Abuse \& Alcoholism2018;6(1):1071.

33. Tsion A MW, Shimeles O, Kifle W. Patient safety practices and medical errors: Perception of health care providers at Jimma University Specialized Hospital, Southwest Ethiopia Open Journal of Preventive Medicine 2012;2(2012):162-70

34. Te. Job satisfaction and associated factors among health professionals working at Western Amhara Region, Ethiopia. Health and Quality of Life Outcomes2018;16(65).

35. Robert A. Pearlman MMB, Jane A, Mary F\& Ellen F. The IntegratedEthicsTM Staff Survey: A Tool to Evaluate and Improve Ethical Practices in Health Care, A JOB Primary Research, 4:1, 7-19, DOI: 10.1080/21507716.2012.752416. AJOB Primary Researc2013.

36. H D. more than kindness. BMC Journal of compassionate health care2015;2(6).

37. Ermias M. KTaAA. Assessment of Health Care Providers Knowledge, Attitude and Practice towards Professional Ethics in Public and Private Health Facilities in Ambo Town, Central Ethiopia. Journal of Biology, Agriculture and Healthcare 2016;8(3).

38. Ephrem D. EB, Hannah G, Hone B., Firew A, Tsigereda B.,Maria M., Aelaf E, Sintayehu A, van den A and Jelle S. Respectful maternity care in Ethiopian public health facilities. Reproductive Health2017.

39. Ulrich CM, Taylor C, Soeken K, Oâ€的Donnell P, Farrar A, Danis M, et al. Everyday ethics: ethical issues and stress in nursing practice. Journal of advanced nursing;66(11):2510-9.

40. Valdez-MartÃnez E, Lavielle P, Bedolla M, Squires A. Ethical behaviours in clinical practice among Mexican health care workers. Nursing ethics2008;15(6):729-44.

41. Bernard A PKF, Mercy N, George O, Yaw Adu-S and Peter D. Knowledge and Perceptions of Health Workers' Training on Ethics, Confidentiality and Medico-Legal Issues. J Clinic Res Bioeth2014;6(1).

42. Kassa H, Murugan R, Zewdu F, Hailu M, Woldeyohannes D. Assessment of knowledge, attitude and practice and associated factors towards palliative care among nurses working in selected hospitals, Addis Ababa, Ethiopia. BMC palliative care;13(1):6.

43. Aragaw Y, Sinishaw W, Daba W, Mekie M. Attitude of Nursing and Midwifery students towards clinical practice and its associated factors in Northwest Ethiopia: a cross-sectional study. BMC research notes;12(1):205.

44. Mukul C AB, Prassana M Abhishek S Adiba S and Rajesh DR. Current Status of Knowledge, Attitudes and Practices towards Healthcare Ethics among Doctors and Nurses from Northern India - A Multicentre Study. Journal of Krishna Institute of Medical Sciences University2013;2(2).

45. Jonas K, Crutzen R, van den Borne B, Reddy P. Healthcare workersâ $€^{\mathrm{TM}}$ behaviors and personal determinants associated with providing adequate sexual and reproductive healthcare services in subSaharan Africa: a systematic review. BMC pregnancy and childbirth;17(1):86. 
46. Gedif G, Sisay Y, Alebel A, Belay YA. Level of job satisfaction and associated factors among health care professionals working at University of Gondar Referral Hospital, Northwest Ethiopia: a crosssectional study. BMC research notes;11(1):824.

47. Haile D, Gualu T, Zeleke H, Dessalegn B. Job Satisfaction and Associated Factors among Nurses in East Gojjam Zone Public Hospitals Northwest Ethiopia, 2016. J Nurs Care;6(398):21671168.1000398.

48. Kolo ES. Job satisfaction among healthcare workers in a tertiary center in kano, Northwestern Nigeria. Nigerian Journal of Basic and Clinical Sciences;15(1):87.

49. Chaulagain N, Khadka DK. Factors influencing job satisfaction among healthcare professionals at Tilganga eye centre, Kathmandu, Nepal. International journal of scientific \& technology research;1(11):32-6.

50. Selamu M, Thornicroft G, Fekadu A, Hanlon C. Conceptualisation of job-related wellbeing, stress and burnout among healthcare workers in rural Ethiopia: a qualitative study. BMC health services research;17(1):412.

51. Elayyan M, Rankin J, Chaarani M. Factors affecting empathetic patient care behaviour among medical doctors and nurses: an integrative literature review. EMHJ;24(3-2018).

\section{Tables}

Table 1: Scio demographic characteristics of health professionals working in public hospital in Bale zone,

Ethiopia, June,2019 (n=408) 


\begin{tabular}{|c|c|c|}
\hline Variable & Number & Percentage \\
\hline Sex & & \\
\hline Male & 262 & 64.2 \\
\hline Female & 146 & 35.8 \\
\hline Religion & & \\
\hline Orthodox & 211 & 51.7 \\
\hline Muslim & 144 & 35.3 \\
\hline Protestant & 49 & 12.0 \\
\hline Other & 4 & 1.0 \\
\hline Ethnicity & & \\
\hline Amhara & 99 & 24.3 \\
\hline Oromo & 295 & 72.3 \\
\hline Other & 14 & 3.4 \\
\hline Age in years & & \\
\hline$<25$ & 63 & 15.4 \\
\hline
\end{tabular}

Page 18/32 


\begin{tabular}{|c|c|c|}
\hline $25-34$ & 258 & 63.2 \\
\hline $35-44$ & 73 & 17.9 \\
\hline$>45$ & 14 & 3.4 \\
\hline Marital status & & \\
\hline Married & 142 & 34.8 \\
\hline Single & 254 & 62.3 \\
\hline Other * & 12 & 2.9 \\
\hline Level of Education & & \\
\hline Diploma & 104 & 25.5 \\
\hline First Degree & 234 & 57.5 \\
\hline Other** & 70 & 15.0 \\
\hline Graduated from & & \\
\hline Public college/university & 84 & 20.6 \\
\hline Private college/university & 320 & 78.4 \\
\hline Profession category & & \\
\hline
\end{tabular}




\begin{tabular}{|c|c|c|}
\hline Medical doctor & 68 & 16.6 \\
\hline Nurse & 259 & 63.5 \\
\hline Midwifery & 81 & 19.9 \\
\hline Work experiences & & \\
\hline$<3$ years & 151 & 37.0 \\
\hline 3-6years & 113 & 27.7 \\
\hline$>6$ years & 144 & 35.3 \\
\hline Salary in Ethiopian Birr (ETB) & & \\
\hline$<3,250$ & 60 & 14.7 \\
\hline $3,250-5414$ & 196 & 48.0 \\
\hline$>5,414$ & 152 & 37.3 \\
\hline & & \\
\hline & & \\
\hline
\end{tabular}

Other* $=$ Widowed, divorced and separated, Other** $=$ master, MD, MD+ specialty certificate

Table 2:Professionalism and other characters of health professionals in Bale zone, June 2019 


\begin{tabular}{|c|c|c|}
\hline Variable & Number & Percentage \\
\hline Happy with your current profession & & \\
\hline Yes & 314 & 77.0 \\
\hline No & 94 & 23.0 \\
\hline Was it your first choice & & \\
\hline Yes & 287 & 70.3 \\
\hline No & 121 & 29.7 \\
\hline Do you advise others to pursue your professio & & \\
\hline Yes & 186 & 45.6 \\
\hline No & 222 & 54.4 \\
\hline Ethics committee in the hospital & & \\
\hline Yes & 171 & 41.9 \\
\hline No & 237 & 58.1 \\
\hline Know the Function of the committee $(n=171)$ & & \\
\hline I don't know & 92 & 53.8 \\
\hline
\end{tabular}




\begin{tabular}{|c|c|c|}
\hline Correction measure & 31 & 18.1 \\
\hline Punishment & 13 & 7.6 \\
\hline Advice & 26 & 15.2 \\
\hline Training & 9 & 5.3 \\
\hline Ever taken professional ethics & & \\
\hline Yes & 131 & 32.1 \\
\hline No & 277 & 67.9 \\
\hline Source of information for prof & & \\
\hline Mass media & 131 & 32.1 \\
\hline College/university & 341 & 83.6 \\
\hline Hospital management & 57 & 14.0 \\
\hline Other & 39 & 9.6 \\
\hline Professional ethics course in c & & \\
\hline Yes adequate & 109 & 26.7 \\
\hline Not adequate & 284 & 69.6 \\
\hline
\end{tabular}




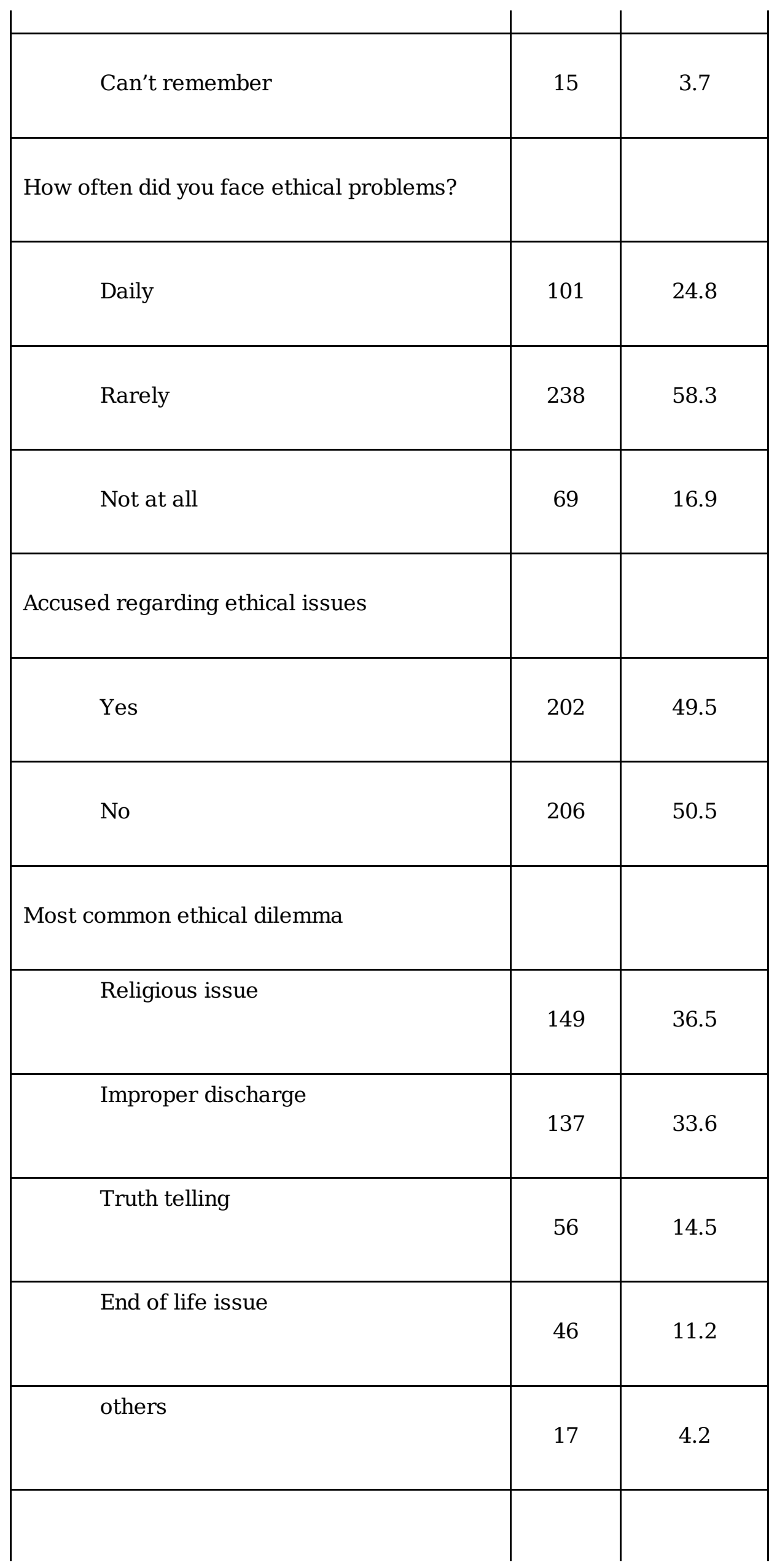




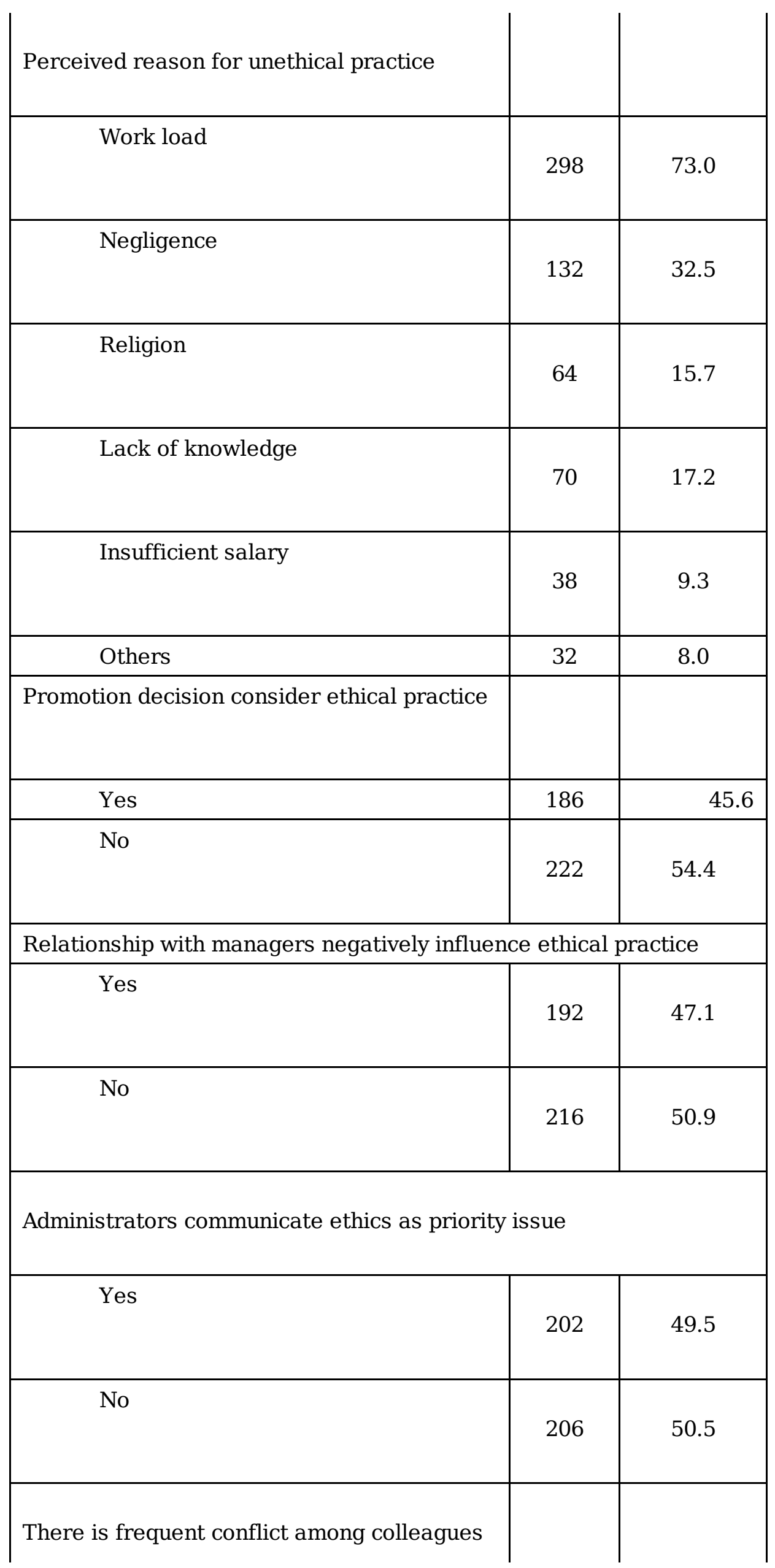




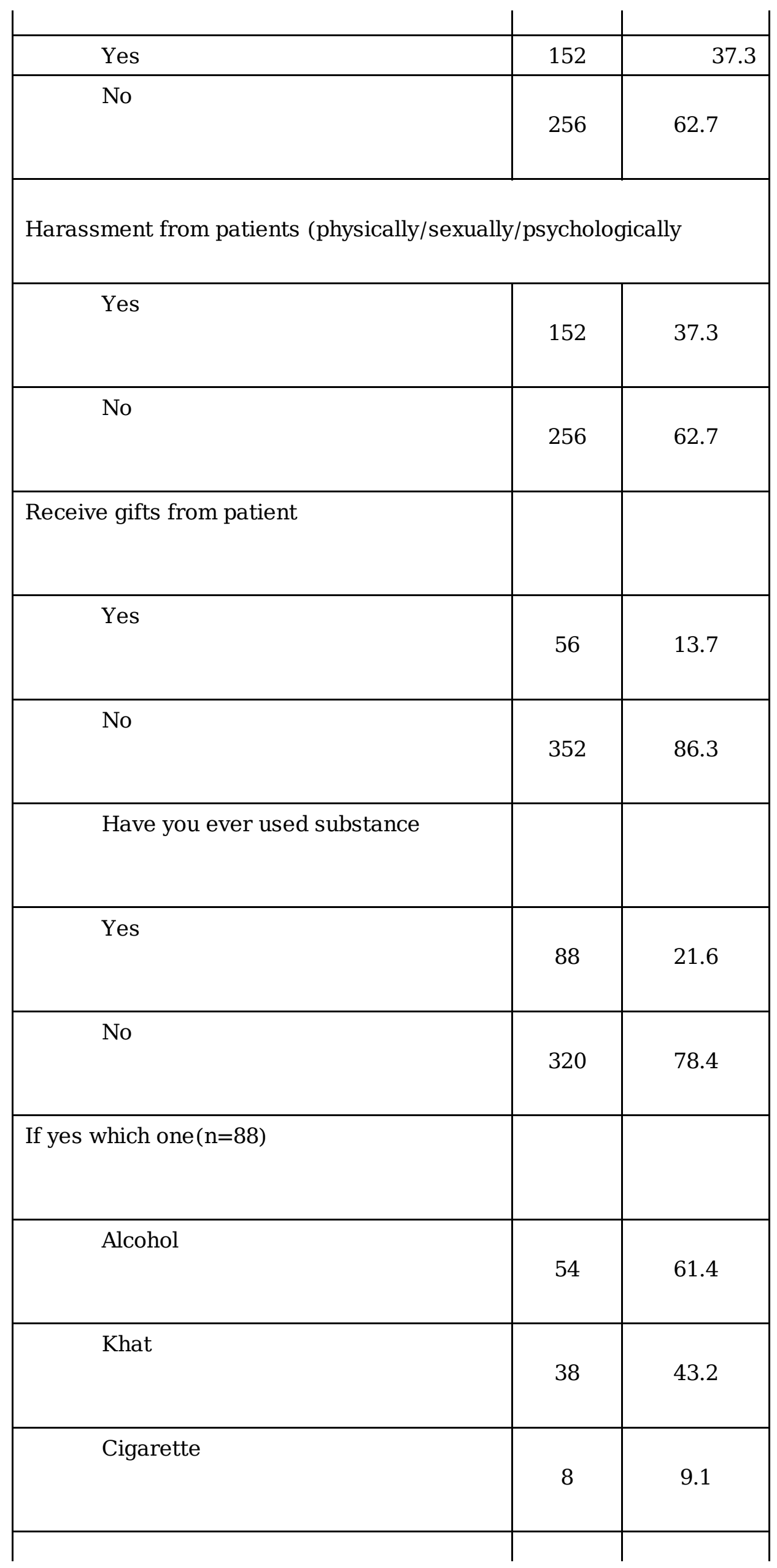




\begin{tabular}{|c|c|c|}
\hline Others & 4 & 4.6 \\
\hline Currently use substance & & \\
\hline Yes & 65 & 15.9 \\
\hline No & 343 & 84.1 \\
\hline If yes which one $(n=65)$ & & \\
\hline Alcohol & 45 & 69.2 \\
\hline Khat & 19 & 29.2 \\
\hline Cigarette & 3 & 4.6 \\
\hline Others & 5 & 7.6 \\
\hline
\end{tabular}

Table 3: Knowledge of health professional towards professional ethics in public hospital in Bale zone, Ethiopia,

June,2019 


\begin{tabular}{|l|c|c|c|c|c|c|}
\hline \multirow{2}{*}{ Item } & \multicolumn{5}{|c|}{ Responses } \\
\cline { 2 - 9 } & \multicolumn{2}{|c|}{ Yes } & \multicolumn{2}{|c|}{ No } & $\underline{\text { I don'tknow }}$ \\
\cline { 2 - 9 } & No & $\%$ & No & $\%$ & No & $\%$ \\
\hline Define professional ethics & 86 & 21.0 & 314 & 77 & 8 & 2.0 \\
\hline Professional ethics is an important subject & 370 & 90.7 & 34 & 8.3 & 4 & 1.0 \\
\hline Right of patient should always be recognized & 305 & 74.8 & 95 & 23.2 & 8 & 2.0 \\
\hline Disclosure of medical report to 3rd party is important & 180 & 44.1 & 209 & 51.2 & 19 & 4.7 \\
\hline Friendly relationship should be established & 293 & 71.9 & 114 & 27.9 & 1 & 0.2 \\
\hline Patient has the right to know about his/her problem & 354 & 86.8 & 50 & 12.2 & 4 & 1.0 \\
\hline Being unethical leads to legal action & 217 & 53.2 & 183 & 44.9 & 8 & 2.0 \\
\hline Patients who wants to die should be assisted & 194 & 36.1 & 251 & 61.5 & 8 & 2.0 \\
\hline Disclosing medical error only if it caused major harm & 177 & 43.4 & 214 & 52.4 & 17 & 4.2 \\
\hline
\end{tabular}

Table 4: The attitudes of healthcare professionals towards professional ethics in public hospitals in Bale,

Ethiopia,June,2019 (n=408) 


\begin{tabular}{|c|c|c|c|c|c|}
\hline Statement & $\begin{array}{c}\mathrm{SA} \\
\mathrm{n}(\%)\end{array}$ & $\begin{array}{c}\mathrm{A} \\
\mathrm{n}(\%)\end{array}$ & $\begin{array}{c}\text { NS } \\
\mathrm{n}(\%)\end{array}$ & $\begin{array}{c}\mathrm{DA} \\
\mathrm{n}(\%)\end{array}$ & $\begin{array}{l}\mathrm{SDA} \\
\mathrm{n}(\%)\end{array}$ \\
\hline $\begin{array}{l}\text { Ethical conduct is important only to avoid legal } \\
\text { action }\end{array}$ & $59(14.5)$ & $149(36.5)$ & $48(11.8)$ & 106(26) & $46(11.2)$ \\
\hline Patient's wishes must always be adhered & $94(23)$ & $215(52.7)$ & $65(15.9)$ & $27(6.6)$ & $7(1.7)$ \\
\hline $\begin{array}{l}\text { Health professionals should do what is best } \\
\text { irrespective of patient's option }\end{array}$ & $70(17.2)$ & 152(37.3) & $53(13)$ & 104(25.4) & 29(7.1) \\
\hline $\begin{array}{l}\text { Patient should always be told if something is } \\
\text { wrong }\end{array}$ & $80(19.6)$ & $195(47.8)$ & $86(21.1)$ & $36(8.8)$ & $11(2.7)$ \\
\hline $\begin{array}{l}\text { Confidential information can only be disclosed if } \\
\text { the patient gives explicit consent }\end{array}$ & 81(19.9) & $170(41.6)$ & $70(17.2)$ & $66(16.2)$ & $21(5.1)$ \\
\hline $\begin{array}{l}\text { Confidentiality cannot be applied in modern care } \\
\text { and should be abandoned }\end{array}$ & $20(4.9)$ & $67(16.4)$ & $65(15.7)$ & $181(44.4)$ & $76(18.6)$ \\
\hline $\begin{array}{l}\text { Close relatives must always be told about the } \\
\text { patient's condition }\end{array}$ & $52(12.7)$ & $130(31.9)$ & $60(14.7)$ & $119(29.2)$ & $47(11.5)$ \\
\hline $\begin{array}{l}\text { Patients need to consent only for operations but } \\
\text { not for tests or medication }\end{array}$ & $28(6.9)$ & $81(19.9)$ & $63(15.4)$ & $161(39.5)$ & $75(18.4)$ \\
\hline $\begin{array}{l}\text { Children should never be treated without the } \\
\text { consent of their parents/guardians }\end{array}$ & $78(19.1)$ & $127(31.2)$ & $72(17.6)$ & $100(24.5)$ & $31(7.6)$ \\
\hline $\begin{array}{l}\text { Health professionals should refuse to treat patient } \\
\text { who behave violently }\end{array}$ & $69(16.8)$ & $88(21.6)$ & $70(17.2)$ & $115(28.2)$ & $66(16.2)$ \\
\hline It is correct to treat social clients first & $18(4.4)$ & $60(14.7)$ & 81(19.9) & 138(33.8) & $111(27.2)$ \\
\hline Report colleague's misconduct is right & $33(8.1)$ & $131(32.1)$ & $113(27.7)$ & $100(24.5)$ & $31(7.6)$ \\
\hline $\begin{array}{l}\text { Patients who refuse treatments due to beliefs } \\
\text { should be instructed to find another health } \\
\text { professionals }\end{array}$ & $40(9.8)$ & 87(21.3) & 75(18.4) & 154(37.7) & $52(12.8)$ \\
\hline $\begin{array}{l}\text { Health professionals should resolve conflict with } \\
\text { other health care providers }\end{array}$ & 95(23.3) & 173(42.4) & $53(13)$ & $44(10.8)$ & 43(10.5) \\
\hline
\end{tabular}


SA=Strongly Agree; A=Agree;NS=Not Sure;DA=Disagree;SDA=Strongly Disagree

Table 5: Ethical practice in public hospitals in Bale, Ethiopia, June, 2019 ( $n=408)$

\begin{tabular}{|l|c|c|c|c|c|c|}
\hline \multirow{2}{*}{ Item } & \multicolumn{5}{|c|}{ Responses } \\
\cline { 2 - 8 } & \multicolumn{2}{|c|}{ Always } & $\underline{\text { Sometimes }}$ & \multicolumn{2}{|c|}{ Never } \\
\cline { 2 - 8 } & No & $\%$ & No & $\%$ & No & $\%$ \\
\hline Introduce yourself, title and professional role & 115 & 28.2 & 258 & 63.2 & 35 & 8.6 \\
Taking informed consent from the patient & 169 & 41.5 & 187 & 45.8 & 52 & 12.7 \\
\hline Order only indicated investigation & 241 & 59.1 & 150 & 36.8 & 17 & 4.1 \\
Showing respect, dignity and attention to patients & 267 & 65.4 & 136 & 33.3 & 5 & 1.3 \\
\hline Using private rooms for patient examination & 148 & 46.3 & 171 & 41.9 & 89 & 21.8 \\
\hline Accepting not to be examined by medical students & 102 & 25 & 227 & 55.6 & 79 & 19.4 \\
\hline Ensuring nobody is present during the examination & 124 & 30.4 & 186 & 45.6 & 98 & 24 \\
\hline Sharing the information without patient's consent & 100 & 24.6 & 134 & 32.8 & 174 & 42.6 \\
\hline Giving the patient right of refuse the treatment & 160 & 39.2 & 202 & 49.5 & 46 & 11.3 \\
\hline Giving decisionsharing opportunity to the patient & 208 & 51 & 184 & 45.1 & 16 & 3.9 \\
\hline Fully informing the patient about cause of illness & 140 & 34.3 & 229 & 56.1 & 39 & 9.6 \\
\hline Refusing services on ground of personal beliefs & 66 & 16.2 & 220 & 53.9 & 122 & 29.9 \\
Issuing genuine and complete sick leave(n=68) & 23 & 33.8 & 41 & 60.3 & 4 & 5.9 \\
Reporting unethical conduct of colleague & 77 & 18.9 & 196 & 48 & 135 & 33.1 \\
Conflict with colleague & 53 & 13 & 245 & 60 & 110 & 27 \\
\hline
\end{tabular}

Table 6: Job satisfaction of healthcare professional in public hospitals in bale zone,Ethiopia,June,2019 (n=408) 


\begin{tabular}{|c|c|c|c|c|c|}
\hline Statement & $\begin{array}{c}\text { VS } \\
\mathrm{n}(\%)\end{array}$ & $\begin{array}{c}\mathrm{S} \\
\mathrm{n}(\%)\end{array}$ & $\begin{array}{c}\mathrm{N} \\
\mathrm{n}(\%)\end{array}$ & $\begin{array}{c}\text { DS } \\
\mathrm{n}(\%)\end{array}$ & $\begin{array}{l}\text { VDS } \\
\mathrm{n}(\%)\end{array}$ \\
\hline Adequacy of equipment's needed for work & $23(5.6)$ & 137(33.6) & $82(20.1)$ & $115(28.2)$ & $51(12.5)$ \\
\hline Interpersonal relations with colleagues & $46(11.3)$ & $204(50)$ & $78(19.1)$ & $59(14.5)$ & $21(5.1)$ \\
\hline Time available for accomplishment of task & $35(8.6)$ & $146(35.8)$ & $108(26.5)$ & $89(21.1)$ & $30(7.4)$ \\
\hline Salary & $8(2)$ & $50(12.3)$ & $34(8.3)$ & $141(34.6)$ & $175(42.8)$ \\
\hline $\begin{array}{l}\text { Opportunities' for continuous professional } \\
\text { education }\end{array}$ & $32(7.8)$ & $124(30.4)$ & $84(20.6)$ & $102(25)$ & $66(16.2)$ \\
\hline $\begin{array}{l}\text { Clarity of instruction regarding the expectation } \\
\text { needed to meet at hospital }\end{array}$ & $24(5.9)$ & 138(33.8) & $110(27)$ & $81(19.9)$ & $55(13.5)$ \\
\hline $\begin{array}{l}\text { Opportunities for professional improvement in } \\
\text { hospital }\end{array}$ & $32(7.8)$ & $115(28.2)$ & $105(25.7)$ & $53(25.3)$ & $53(13)$ \\
\hline
\end{tabular}

VS=Very satisfied; S=Satisfied; N=Not neutral; DS=Dissatisfied; VDS=Very Dissatisfied

Table 7: Factors associated with health workers practice on professional ethics, Bale zone, Ethiopia, June, 2019 


\begin{tabular}{|c|c|c|c|c|c|c|}
\hline \multirow[t]{2}{*}{ Variables } & \multicolumn{2}{|c|}{ Ethical practice } & \multirow{2}{*}{$\begin{array}{c}\text { COR } \\
(95 \% \mathrm{CI})\end{array}$} & \multirow[t]{2}{*}{ P-Value } & \multirow{2}{*}{$\begin{array}{c}\text { AOR } \\
(95 \% \mathrm{CI})\end{array}$} & \multirow[t]{2}{*}{ P-Value } \\
\hline & Poor & Good & & & & \\
\hline \multicolumn{7}{|c|}{ Knowledge towards professional ethics } \\
\hline Good & 110 & 119 & 1 & & 1 & \\
\hline Poor & 112 & 67 & $1.8[1.21-2.69] *$ & 0.004 & $1.42[0.89,2.26]$ & 0.141 \\
\hline \multicolumn{7}{|c|}{ Attitude towards professional ethics } \\
\hline Positive attitude & 84 & 100 & 1 & & & \\
\hline Negative attitude & 138 & 86 & $1.9[1.29-2.83]^{*}$ & 0.001 & $1.61[1.03,2.52]^{* *}$ & 0.035 \\
\hline \multicolumn{7}{|l|}{ Current profession } \\
\hline GP & 26 & 42 & 1 & & 1 & \\
\hline Nurse & 141 & 118 & $1.93[1.12,3.34]^{*}$ & 0.012 & $3.01[1.17,7.76]^{* *}$ & 0.02 \\
\hline Midwife & 55 & 26 & $3.4[1.74,6.72]^{*}$ & $<0.01$ & $4.11[1.49,11.4]^{* *}$ & 0.06 \\
\hline \multicolumn{7}{|l|}{ Educational status } \\
\hline Diploma & 56 & 48 & $1.71[0.92,3.17]$ & 0.88 & $2.223[0.77,6.40]$ & 0.139 \\
\hline Degree & 137 & 97 & $2.07[1.12,3.57]^{*}$ & 0.09 & $1.53[0.62,3.76]$ & 0.35 \\
\hline Others & 28 & 41 & 1 & & 1 & \\
\hline \multicolumn{7}{|l|}{ Work Experience } \\
\hline$<3$ years & 91 & 60 & $1.7[1 \cdot 10,2.77]^{*}$ & 0.018 & $2.50[1.32,4.75]^{* *}$ & 0.003 \\
\hline 3-6 years & 64 & 49 & $1.5[0.91,2.46]$ & 0.11 & $1.46[0.83,2.54]$ & 0.187 \\
\hline$>6$ years & 67 & 77 & 1 & & 1 & \\
\hline \multicolumn{7}{|c|}{ Do you like your profession } \\
\hline Yes & 162 & 152 & 1 & & & \\
\hline No & 60 & 32 & $1.656[1.03,2.66]^{*}$ & 0.038 & $0.670[0.393,1.14]$ & 0.14 \\
\hline \multicolumn{7}{|c|}{ Receive gifts from patients } \\
\hline Yes & 39 & 17 & $2.12[1.16,3.39]$ & $0.015^{*}$ & $1.72[0.89,3.34]$ & 0.11 \\
\hline No & 183 & 169 & 1 & & 1 & \\
\hline \multicolumn{7}{|l|}{ Salary } \\
\hline$<3250$ & 42 & 18 & $2.16[1.14,4.08]^{*}$ & 0.018 & $0.52[0.20,1.32]$ & 0.17 \\
\hline $3250-5414$ & 101 & 95 & $0.99[0.64,1.5]$ & 0.93 & $0.41[0.21,0.78]$ & 0.007 \\
\hline$>5414$ & 79 & 7 & 1 & & 1 & \\
\hline \multicolumn{7}{|c|}{ Presence of ethics committee } \\
\hline Yes & 73 & 98 & 1 & & 1 & \\
\hline No & 149 & 88 & $2.3[1.52,3.40]^{*}$ & 0.01 & $1.58[0.99,2.50]$ & 0.51 \\
\hline \multicolumn{7}{|c|}{ Adequacy of professional ethics in curriculum } \\
\hline Adequate & 41 & 68 & 1 & & & \\
\hline Not adequate & 172 & 112 & $2.5[1.62,4.01]^{*}$ & 0.00 & $1.79[1.08,2.97]^{* *}$ & 0.025 \\
\hline Can't remember & 9 & 6 & $2.5[0.83,7.50]$ & 0.11 & $1.653[0.50,5.47]$ & 0.41 \\
\hline
\end{tabular}


*Significant association $(\mathrm{p}<0.05)$ crude. **Significant association, $(\mathrm{p}<0.05)$ adjusted.

Others $=$ MD, MD+Speciality, MSC 